\title{
Knowledge and Awareness about Periodontitis Associated with the Orthodontic Treatment among the Dental Doctors of Dammam, KSA
}

Abdulrahman Ahmed Mohammed Abushiqa*

Safwa General Hospital, Dammam, KSA

DOI: 10.36348/sjodr.2020.v05i06.008

| Received: 16.06 .2020 | Accepted: 24.06.2020 | Published: 30.06 .2020

*Corresponding author: Abdulrahman Ahmed Mohammed Abushiqa

\section{Abstract}

The orthodontic treatments are associated with the movement of the tooth achieved by the involvement of the periodontal ligament that unites the roots of the tooth with the alveolar bone. The forces used to achieve best results for the orthodontic treatment creates stress on the periodontal ligament that promotes traction of bone, bone resorption and tooth movement. During the process of the orthodontic treatment it is essential to maintain a healthy periodontium. Mostly the fixed orthodontic treatment could deteriorate periodontal health because of the wear and tear of the biofilm that access the pathogenic micro-flora to grow. In this study the knowledge and awareness of the dental doctors in Dammam is surveyed to determine the association of periodontitis with the orthodontic treatment. About 89 dental doctors participated in this study, $66(74.2 \%)$ were female participants and $23(25.8 \%)$ were male participants. Around 87 (97.7\%) of the dental doctors of Dammam feels that periodontal complications are caused in the patients treated with orthodontics. The dental Doctors of Dammam have comparatively good knowledge about the relationship between the orthodontic treatment and the periodontal diseases. The orthodontist and the periodontist need to do research and development to avoid the periodontal disease during and after the orthodontic treatment.

Keywords: orthodontic treatment, periodontal ligament, periodontitis, bone-resorption, orthodontist, periodontist.

Copyright @ 2020: This is an open-access article distributed under the terms of the Creative Commons Attribution license which permits unrestricted use, distribution, and reproduction in any medium for non-commercial use (NonCommercial, or CC-BY-NC) provided the original author and source are credited.

\section{INTRODUCTION}

"Orthodontics" is a branch of dentistry that deals with Malocclusion of the teeth. Malocclusion is a condition in which the positioning of the teeth is not correct, when the mouth is closed which may result in an improper bite [1]. The specialist dealing with the orthodontic treatment is called as the "orthodontist", who helps in making the teeth straight.

Orthodontic treatment is basically done to improve the oral functioning of the mouth as well as to enhance a person's appearance. After the orthodontic treatment better chewing and speech function are attained [2]. Apart from this the orthodontist also carries out work to close the wide gaps between the teeth, align the tips of the teeth, straighten the crooked teeth, boosts the long-term health of the gum and prevents excessive wear out of the teeth.

In order to achieve all these results after the orthodontic treatment, the orthodontist uses a wide variety of medical dental devices that includes braces, plates and headgear. The orthodontic treatment is also associated with a wide variety of adverse effects like the root resorption, gingivitis, periodontitis and temporomandibular dysfunction (TMD) [3].

Before carrying out the orthodontic treatment the orthodontist should be well aware of all the side effects and the risk factors associated with the orthodontic treatment. The risk factors that are related with the orthodontic treatment are the duration of the treatment, the trauma history, the cleaning habits of the teeth, the length and shape of the root and genetic factors.

One of the most common side effect of the orthodontic treatment is periodontitis, that is inflammation of the supporting tissues of the teeth. The periodontitis is basically caused by development of certain micro-organism that may lead to the destruction of the periodontal ligament and alveolar bone with pocket formation [4].

The common periodontal complications that are associated with the orthodontic treatment basically includes periodontitis, gingival bleeding, gingival recession, alveolar bone loss, fenestration, dehiscense, 
inter-dental fold and black triangle formation in the gums. The basic factors that is responsible for the initiation, progression and the recurrence of the periodontitis is the microbial flora accumulation and development. The Other risk factors that are associated with the periodontal complications includes the techniques used in the orthodontic treatment as well as the patient factors [5]. The patient factors may be history of the periodontal disease and poor oral hygiene and smoking. The main important factors in the development of the gingivitis is the presence of plague [6].

During the orthodontic treatment the medical devices like the orthodontic brackets and elastics interfere with effective cleaning of the dental plaque increases the chances of getting gingivitis. Another important factor is poor oral hygiene maintained by the patient before and during the process of the orthodontic treatment, especially in the molar region due to the presence of the molar bands that may cause the food lodgement. Due to the food lodgement, the bacteria may be developed in that area that may lead to the formation of dental plaque, that increases the risk factors for gingivitis [7]. Growth of the periodontal Bacteria is observed with minimal amount of gingival inflammation during this condition [4]. It was reported that the inflammation of the gingivial can be minimal if adequate amounts of orthodontic forces are applied on the periodontal tissue support region. A researcher reported that if the fixed appliance is kept for over a long period of time the periodontal destruction is minimal.

If the periodontal issues are not taken care of during the orthodontic treatment then it could lead to major complications and unhealthy oral cavity. Thus as we understand from the earlier research done in this field of dentistry, that proves that orthodontic treatment can lead to periodontal diseases if proper measures are not made during the treatment. Therefore the knowledge and awareness about the periodontitis during the orthodontic treatment among the dental doctors of Dammam region is very crucial and hence we choose to study this topic.

\section{METHODOLOGY \\ Research instrument}

To carry out the survey about the knowledge and awareness related to periodontitis during the orthodontic treatment among the dental doctors of Dammam region a pre-designed, pre-validated and selfadministered questionnaire was circulated online to dental doctors of Dammam region in Saudi Arabia. This survey was carried out in the year 2020. The questionnaire was originally formulated in the English language and later translated in Arabic language. This survey questionnaire included the questions related to Demographic characters of the dental doctors and also the knowledge and awareness questions about periodontitis during the orthodontic treatment.

About 89 dental doctors answered the questionnaire the inclusion factor is dental doctors, residing in Dammam. The exclusion factor is any participant apart from the dental doctors and residing in cities other than Dammam in Saudi Arabia.

\section{Statistical methods}

The data was collected in the pre-designed tables and this data was analysed using the computer software SPSS. The frequencies and percentages of the responses from the dental doctors in Dammam, Saudi Arabia were done using the P-value equal to or less than 0.05 . The descriptive statistics were attained, and the mean, standard deviation, and frequency distribution were calculated. All the data collected was kept confidential.

\section{RESULTS}

Among the 89 dental doctors participating in the survey, $28(31.5 \%)$ were general doctors, $24(27 \%)$ were dental specialist and $37(41.5 \%)$ were dental interns. Most of the participants, about 41 (46\%) belonged to the age group 21-30 years, followed by 16 $(18 \%)$ in $31-40$ years, $15(16.9 \%)$ in $51-60$ years, 11 $(12.5 \%)$ in $41-50$ years age group with least $2(2.1 \%)$ above 60 years.

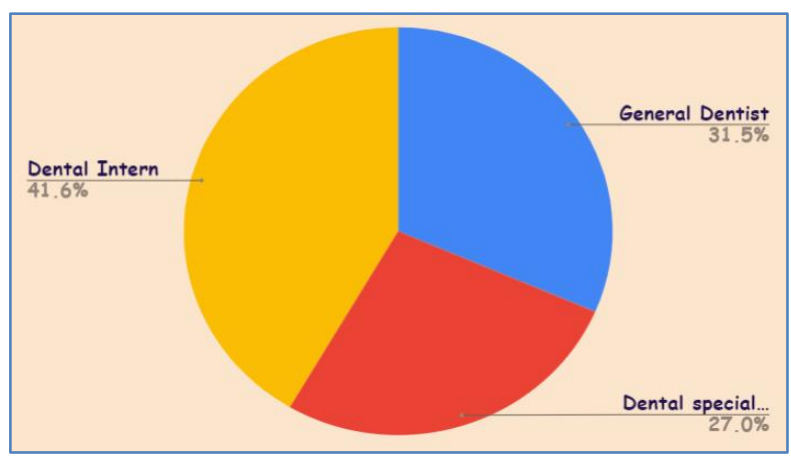

About $66(74.2 \%)$ were female participants and $23(25.8 \%)$ were male participants as shown in the table below. 


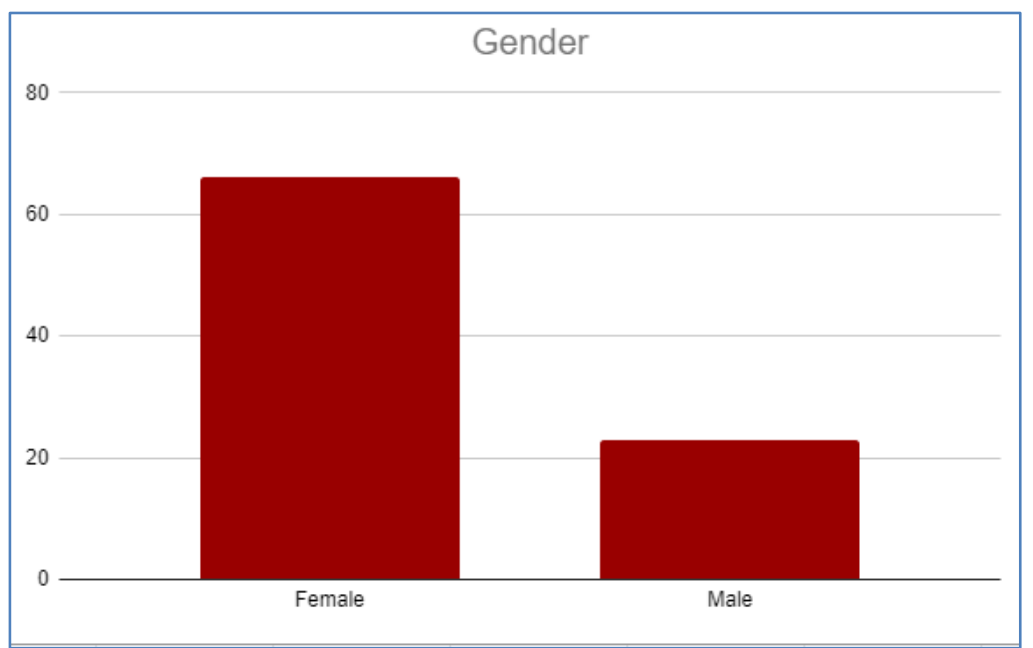

$35(39.3 \%)$ of the participants had less than 1 year of professional experience, $24(27 \%)$ had 2 years' experience, $15(16.9 \%)$ had about 3 years of experience,
$11(12.4 \%)$ had 4 years of professional dental experience and only $4(4.4 \%)$ had more than 5 years' experience.

\begin{tabular}{|l|l|l|}
\hline DEMOGRAPHIC CHARACTERS & FREQUENCY & PERCENTAGE \\
\hline Professional status & & \\
General dentists & 28 & 31.5 \\
Dental Specialists & 24 & 27 \\
Dental Intern & 37 & 41.5 \\
\hline Age & & \\
<20 years & 4 & 4.5 \\
21-30 years & 41 & 46 \\
31-40 years & 16 & 18 \\
41- 50 years & 11 & 12.5 \\
51-60 years & 15 & 16.9 \\
$>$ 60 years & 2 & 2.1 \\
\hline Gender & & \\
Female & 66 & 74.2 \\
Male & 23 & 25.8 \\
\hline Professional Experience & & \\
<1 year & 35 & 39.3 \\
2 years & 24 & 27 \\
3 years & 15 & 16.9 \\
4 years & 11 & 12.4 \\
>5 years & 4 & 4.4 \\
\hline
\end{tabular}

To estimate the knowledge of the dental professionals about the periodontitis associated with orthodontic treatment, this survey included knowledge based questions that showed the following results mentioned in the table below. About $74(83.1 \%)$ think that orthodontic treatment could cause swollen gingiva, $81(91 \%)$ thought that orthodontic treatment could result in aching gums during and after the treatment in the patients. $78(88.8 \%)$ thinks that sensitive gums are associated with the orthodontic treatment, 74 (83.4\%) reported that orthodontic treatment can cause bleeding gums, $69(77.5 \%)$ thinks that recession is caused during the orthodontic treatment, $80 \quad(90 \%)$ thinks that orthodontic treatment may lead to tooth hypersensitivity, $83(93.3 \% 0)$ thinks that tooth mobility is caused by the orthodontic treatment, $71(80 \%)$ dental professionals reported that occlusion may occur during the orthodontic treatment and $75(84.3 \%)$ thinks that halitosis is reported by the patients during the orthodontic treatment. $63(70.7 \%)$ of the dental professionals have knowledge that bad taste is reported by the patients during and after the orthodontic treatment. 
Abdulrahman Ahmed Mohammed Abushiqa; Saudi J Oral Dent Res, June, 2020; 5(6): 295-300

\begin{tabular}{|l|l|l|}
\hline PERIODONTITIS ASSOCIATED WITH ORTHODONTIC TREATMENT & Yes & No \\
\hline Are you aware that orthodontic treatment may cause swollen gingiva? & $74(83.1 \%)$ & $15(16.9 \%)$ \\
\hline $\begin{array}{l}\text { Are you aware that orthodontic treatment may cause aching gums during and after } \\
\text { treatment? }\end{array}$ & $81(91 \%)$ & $8(9 \%)$ \\
\hline Are you aware that orthodontic treatment may cause sensitive gums? & $78(88.8 \%)$ & $12.2 \%)$ \\
\hline Are you aware that orthodontic treatment may cause bleeding gums? & $74(83.1 \%)$ & $15(16.9 \%)$ \\
\hline Are you aware that orthodontic treatment may cause Recession? & $69(77.5 \%)$ & $20(32.5 \%)$ \\
\hline Are you aware that orthodontic treatment may cause tooth hypersensitivity? & $80(90 \%)$ & $9(10 \%)$ \\
\hline Are you aware that orthodontic treatment may cause tooth mobility? & $83(93.3 \%)$ & $6(6.7 \%)$ \\
\hline Are you aware that orthodontic treatment may cause tooth migration? & $82(91 \%)$ & $8(9 \%)$ \\
\hline Are you aware that orthodontic treatment may cause change in occlusion? & $71(80 \%)$ & $18(20 \%)$ \\
\hline Are you aware that orthodontic treatment may cause halitosis? & $75(84.3 \%)$ & $14(15.7 \%)$ \\
\hline Are you aware that orthodontic treatment may cause bad taste? & $63(70.7 \%)$ & $26(29.3 \%)$ \\
\hline
\end{tabular}

About $87(97.7 \%)$ of the dental doctors of Dammam feels that periodontal complications are caused in the patients treated with orthodontics.

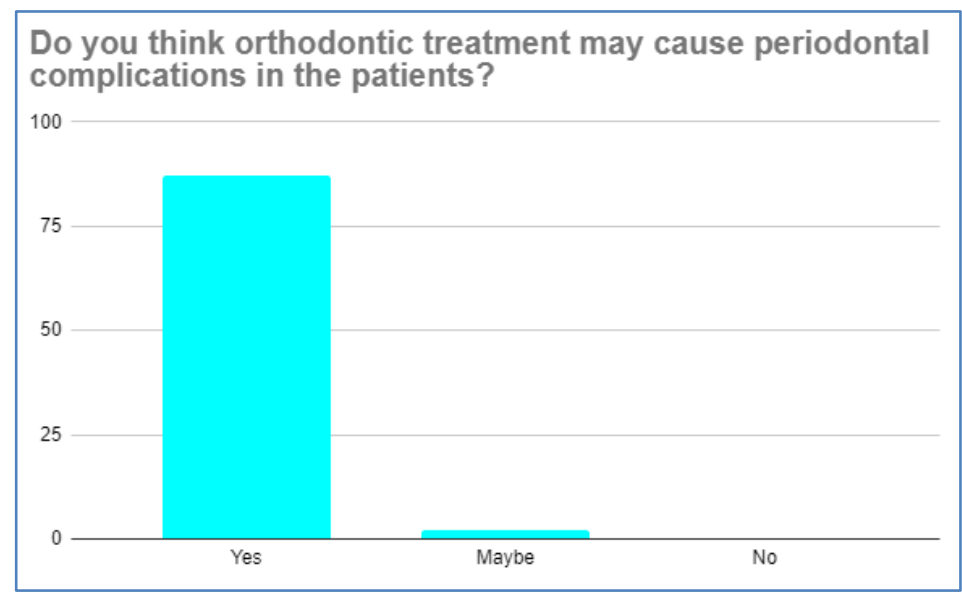

$49(55 \%)$ examine for the periodontal disease in the patients that had undergone orthodontic treatment. $35(39.3 \%)$ of the participants may prefer their patients to a specialists, $74(83.1 \%)$ reported that simple diagnosis of the periodontal disease is easy to perform and $36(40.4 \%)$ of the dental doctors had taken special training related to the periodontal diseases.

\begin{tabular}{|l|l|l|l|}
\hline $\begin{array}{l}\text { PERIODONTITIS ASSOCIATED WITH } \\
\text { ORTHODONTIC TREATMENT }\end{array}$ & Yes & Maybe & No \\
\hline $\begin{array}{l}\text { Do you think orthodontic treatment may cause periodontal } \\
\text { complications in the patients? }\end{array}$ & $87(97.7 \%)$ & $2(22.3 \%)$ & $0(0 \%)$ \\
\hline $\begin{array}{l}\text { Do you examine for periodontal disease in patients that had } \\
\text { undergone orthodontic treatment? }\end{array}$ & $49(55 \%)$ & $38(42.7 \%)$ & $2(2.3 \%)$ \\
\hline Do you prefer your patient to a specialists? & $21(23.5 \%)$ & $35(39.3 \%)$ & $33(37.2 \%)$ \\
\hline Are you convenient to perform a simple periodontal diagnosis? & $74(83.1 \%)$ & $11(12.4 \%)$ & $4(4.6 \%)$ \\
\hline Do you have special training about the periodontal diseases? & $36(40.4 \%)$ & $24(27 \%)$ & $29(32.6 \%)$ \\
\hline
\end{tabular}

\section{DISCUSSION}

The periodontal disease is an infectious disease that is caused by the gram-negative and anaerobic bacteria. The periodontal diseases are basically categorized into gingivitis and periodontitis [8]. About $68 \%$ of the adult Saudi population is known to have the periodontal diseases whereas in the United States of America about $50 \%$ of the population suffers from it. The literature related to periodontal diseases and orthodontic treatment in Saudi Arabia was limited and had very less researches done on this. The association between the orthodontic treatment and the periodontal diseases is reported in the literature of both orthodontics and periodontists [9].

The permanent orthodontic appliances applied to the teeth of the patient may cause the accumulation of Biofilm in the Supra gingival region and this can damage the periodontal health of the patient [10]. The deterioration of the tooth surface may also lead to the accumulation of the biofilm of pathogenic anaerobic bacteria in the supra and the sub-gingival region [11]. 
Thus the patients after the orthodontic treatment should be made aware of the the importance and significance of the oral hygiene and should be trained to use toothbrush and Dental floss in a proper order during the orthodontic therapy [12]. The periodontal complications that are associated with it include gingivitis; gingival recession; dehiscense; periodontitis; alveolar bone loss; dark Triangles; hypertrophy [13]. The periodontal disease that is associated with orthodontic treatment if not treated properly, it can lead to the formation of the periodontal pockets that may eventually lead to the multiple tooth loss [14].

The orthodontic treatment is certainly related with biological factors that are patient dependent and treatment dependent [15]. According to Needleman in the year 2015 Oral Hygiene instructions and the professional oral hygiene treatment which is to reduce the micro-organisms and the inflammation causing the periodontal disease is need to be imparted to the patients; hence the knowledge about this to the dental doctors is of utmost importance [16].

Review of the literature found that there were no controlled clinical trials that carried out on the orthodontic treatment in patients suffering from periodontal diseases in Saudi Arabia. The scarcity of such findings proves to be a good rationale for this study.The orthodontist and the periodontist need to do research and development to avoid the periodontal disease during and after the orthodontic treatment.

The dental Doctors of Dammam have comparatively good knowledge about the relationship between the orthodontic treatment and the periodontal diseases. Training should be provided to the dental interns as part of their course completion about the periodontal related issues and complications during and after the orthodontic treatment.

\section{CONCLUSION}

The periodontal diseases and the orthodontic treatment are both interrelated and a lot of Investigation has been going on this even today. The main objective of the orthodontic treatment is to to prolong the life of the teeth and promote Dental health by reducing the occlusal trauma. The malocclusion can cause the oral periodontal health issues. As it was found reasonable that the teeth that are properly arranged and straight are easier to clean and the hence it correctly promotes healthier gums.

s found by this survey, most of the participants about 37 $(41.5 \%)$ were dental interns, followed by the general dentist $28(31.5 \%)$ and the dental Specialists $24(27 \%)$. Most of the dental doctors were in age group 21 to 30 years that is $41(46 \%)$ Majority of the dental doctors about 66 (70 4.2) were female and $23(25.8 \%)$ were males.
About 35 that is $39.3 \%$ of the total dental doctors that participated in this survey had less than one year of experience, while $24(27 \%)$ have 2 years of experience, $15(16.9 \%)$ have 3 years of experience and $11(12.4 \%)$ have 4 years of experience and $4(4.4 \%)$ have more than 5 years of experience.

It was analysed that 74 (80 3.1\%) were aware that orthodontic treatment may cause swollen gingiva; $81(91 \%)$ were aware that orthodontic treatment may cause pain in gums during and after the treatment; 70 $(88.8 \%)$ were aware that orthodontic treatment can cause sensitive gums; $74(83.1 \%)$ were familiar that orthodontic treatment can cause bleeding gums. 87 $(97.7 \%)$ thinks that orthodontic treatment can cause the periodontal complications in the patient $49(55 \%)$ of the dental doctors examined for periodontal disease in patients that had undergone orthodontic treatment in the past. $35(39.3 \%)$ preferred patients to a periodontologists. 74 (83. 1\%) of the dental doctors were convenient to perform a simple periodontal diagnosis on their patients and about 36 (44\%) had undergone special training about the periodontal disease.

If Maintained in a proper order, the periodontal disease can be controlled in the patients who have undergone the orthodontic treatment safely and satisfactory. However the long-term studies that had been carried out to understand the relationship between the orthodontic treatment and the periodontal diseases showed that there is no difference between the occurrence of the periodontal disease in post orthodontic patients and the non-orthodontic patients. If the orthodontist shows a reduction in the force moments on the teeth then it can reduce the alveolar bone loss. However the clinical experience of the orthodontic treatment of the patients have been shown to successfully control the chronic periodontal disease if not treated property orthodontics can promote periodontal disease in spite of the fact that basically orthodontics is known to reduce the symptoms of the periodontal disease.

\section{ETHICAL CONSIDERATION}

\section{Compliance with ethical standards}

Ethical approval: This article contains a survey with the evaluation of knowledge and awareness about the periodontitis associated with the orthodontic treatment among the dental doctors in Dammam, Saudi Arabia.

Conflict of interest: All the authors do not have any commercial associations that might pose or create a conflict of interest with information presented in this communication. No intramural or extramural funding supported any aspect of this work. 


\section{REFERENCES}

1. Bloom, R.H., Brown, L.R. (1964). A study of the effects of orthodontic appliances on oral microbiological flora. Oral Surg Oral Med Oral Path, 17:658-667.

2. Zachrisson, S., Zachrisson, B.U.(1972). Gingival condition associated with orthodontic treatment. Angle Orthod, 42:26-34.

3. Socransky, S.S., Haffajee, A.D.(1992). The bacterial etiology of destructive periodontal disease: current concepts. J Periodontol, 63(4 Suppl):322-31.

4. Bollen, A.M., Cunha-Cruz, J., Bakko, D.W., Huang, G.J., Hujoel, P.P.(2008). The effects of orthodontic therapy on periodontal health: a systematic review of controlled evidence. J Am Dent Assoc, 139(4):413-22.

5. Bernimoulin, J.P. (2003). Recent concepts in plaque formation. J Clin Periodontol, 30 Suppl 5:7-9

6. Hamp, S.E., Johansson, L.A.(1982). Dental prophylaxis for youths in their late teens. I. Clinical effect of different preventive regimes on oral hygiene, gingivitis and dental caries. J Clin Periodontol, 9:22-34.

7. Boyd, R.L., Murray, P., Robertson, P.B.(1989). Effect of rotary toothbrush versus manual toothbrush on periodontal status during orthodontic treatment. Am J Orthod Dentofac Orthop, 96:342-347.

8. Del Santo, M. (2012). Periodontium and orthodontic implications: clinical applications. Int J Stomatol Res, 1(3):17-23.
9. Alstad, S., Zachrisson, B.U.(1979). Longitudinal study of periodontal condition associated with orthodontic treatment in adolescents. Am J Orthod, 76:277-286.

10. Polson, A.M., Subtelny, J.D., Meitner, S.W., Polson, A.P., Sommers, E.W., Iker, H,P., Reed, B.E. (1988). Long term periodontal status after orthodontic treatment. Am J Orthod Dentofac Orthop, 93:51-58.

11. Eliasson, L.A., Hugoson, A., Kurol, J., Siwe, H.(1982). The effects of orthodontic treatment on periodontal tissues in patients with reduced periodontal support. Eur J Orthod, 4:1-9.

12. Alexander, S.A.(1991). Effects of orthodontic attachments on the gingival health of permanent 2nd molars. Am J Orthod Dentofac Orthop, 199:337-340.

13. Yared, K.F., Zenobio, E.G., Pacheco, W. (2006). Periodontal status of mandibular central incisors after orthodontic proclination in adults. Am J Orthod Dentofacial Orthop, 130:6.e1-8.

14. Liu, H., Sun, J., Dong, Y., Lu, H., Zhou, H., Hansen, B.F. (2011). Periodontal health and relative quantity of subgingival Porphyromonas gingivalis during orthodontic treatment. Angle Orthod, 81:609-15.

15. Joss-Vassalli, I., Grebenstein, C., Topouzelis, N., Sculean, A., Katsaros, C.(2010). Orthodontic therapy and gingival recession: A systematic review. Orthod Craniofac Res, 13:127-41.

16. Needleman, I., Nibali, L., \& Di Iorio, A. (2015). Professional mechanical plaque removal for prevention of periodontal diseases in adults-systematic review update. Journal of Clinical Periodontology 42 (Suppl 16), S12-S35. 